\title{
MAKING THE GLASS DISK FOR A 70-INCH TELESCOPE REFLECTOR
}

\author{
By A. N. Finn
}

ABSTRACT

Details are given of the procedure followed in making a glass disk 70 inches in diameter and 11 inches thick for use as a reflector in an astronomical telescope. These include the making of the pots, the modifications in the construction of the melting furnace, the construction of the mold and annealing furnace, the methods of measuring and controlling temperatures, the melting and casting of the glass, essential data on annealing the glass, the determination of the quality of annealing (the amount and distribution of the residual strain), and the drilling of the hole to accommodate a Cassegrainian mounting.

\section{CONTENTS}

II. Plan of the work

III. The pots

IV. The melting furnace

V. Essentials of method finally used

VI. Placing and assembling the mold ....... 320

VII. Temperature measurements . .

VIII. Heating current installation

IX. Procedure

X. Casting and annealing the glass_.

XI. Final cooling _... 327

XII. Inspection during cooling _.

XIII. Quality of annealing

XIV. Drilling the hole..... 328

XV. Conclusion. 329

\section{INTRODUCTION}

The art of making glass probably dates from about 1600 B. C., when the Egyptians made crude glass vessels by gathering molten glass on clay or sand forms. The glass of that period was similar to the older enamels or glazes and was generally more or less opaque. It contained many inclusions of undissolved matter and was generally highly colored either by iron compounds unavoidably present in the raw materials from which the glass was made or by some 
coloring matter, such as minerals containing cobalt and copper intentionally added.

During succeeding centuries, as the art was developed, glass making became an established industry and the quantity and quality of the product improved. It has only been within the last century, however, that glass making became a problem of scientific interest, and the resulting improvements made soon led to the production of glasses free from color, opaque inclusions, and other visible defects, and to the manufacture of glasses having certain definite compositions. Such glasses have definite optical properties, and some of them are used in the construction of precision optical instruments and consequently are referred to as optical glasses.

Marked progress in the optical-glass industry dates from about 1850. Since then the developments have been such that optical instruments containing small pieces of glass are now quite common. Optical instruments, such as large telescopes, are, however, not common, probably because of a lack of demand for them, but unquestionably this in turn is to a great extent the result of the cost of the equipment and difficulties met in securing suitable glass. The number of large telescopes in the world is relatively small, and among these the 40-inch refractor at the Yerkes Observatory and the 100inch reflector at Mount Wilson are the largest of their respective types.

The manufacture of glass for ordinary optical instruments is a well-established but limited industry, there being probably not more than 10 optical-glass plants in the world. This industry is, however, very necessary for the maintenance and development of our commercial and scientific enterprises, since a lack of suitable glass for making microscopes, cameras, surveying instruments, range finders, etc., would greatly hamper all work in which such instruments are used.

Difficulties which are of minor importance in making glass for smaller optical instruments become more serious as the size of the instrument, and consequently the size of the glass, is increased. The most serious difficulties met in producing large pieces of glass include properly melting the amount of glass required, transferring it to a mold to produce the desired shape while maintaining the necessary quality, and finally cooling it at rates such that it does not crack and that it will be well annealed (free from disturbing internal stresses).

The proper cooling (annealing) of large pieces of glass is probably the most exacting and tedious phase of the work, and this can not be successfully accomplished without knowing the thermal properties of the glass and adequately controlling the temperatures of the annealing furnace. 


\section{PLAN OF THE WORK}

Because of the lack of definite information on methods of making satisfactory pieces of glass which could be used for large telescope reflectors, the Bureau of Standards became interested in the problem and undertook to make the glass for a 61-inch reflector. Such a reflector should be 10 inches thick when finished and, if made of a borosilicate crown glass, would weigh approximately 2,960 pounds.

In planning this work it was decided to make the disk about 70 inches in diameter and 15 inches thick in order to make ample allowance for faulty edges. A piece of glass having these dimensions would weigh approximately 5,000 pounds. The first plan decided on involved the melting of the glass in one large pot and cooling it in such a way that the glass would not crack and so that the pot would spall from the glass. Having obtained a piece of glass of sufficient size, it would then be put in a mold of the required diameter and an electric furnace built around it so that the glass might be slowly heated until it became soft enough to flow and fill the mold uniformly; after this it would be cooled to the proper annealing temperature and annealed. Four attempts to obtain the initial piece of glass were unsuccessful because the glass cracked each time during cooling. This method was then discarded and a different one tried. In the new method the glass was to be melted in a pot provided with a hole near the bottom, this hole being stopped with a water-cooled metal plug. When the glass was properly melted a metal trough was to be placed between the pot and mold, the plug removed, and the glass allowed to flow into the mold where it would be ready for cooling and annealing.

The successful application of this method depended on three major conditions: (1) Preventing the glass from leaking through the hole in the pot by means of a water-cooled metal plug, (2) adequately controlling the flow of glass from the pot to the mold, and (3) obtaining a satisfactory friable lining for the mold. The advantage of this over the first method tried was that only one cooling of a large and relatively thin slab would now be required, whereas the first one offered three additional hazards: (1) The possibility of the glass cracking during the initial cooling on account of its great thickness, (2) the possible failure of the pot to break away from the glass, and (3) the possibility of cracking the glass during reheating for softening in the mold.

\section{THE POTS}

Before any of this work was done it was necessary, of course, to make pots sufficiently large to hold the amount of glass required. The dimensions of the furnace available for the purpose determined, to a large extent, the actual dimensions of the pots, which had, after 
burning, a depth of 33.3 inches and an internal diameter of 47 inches at the top and 43 inches at the bottom. The pot walls were $31 / 2$ and $4 \frac{1}{2}$ inches thick at the top and bottom, respectively. (See fig. 2 for a cross-section view of the pot.) The pots were "cast" in a plaster of Paris mold by a method developed at this bureau ${ }^{1}$ and used in making all of our glass pots, but, since these large pots were more than six times the size of our ordinary melting pots, it was necessary to make a larger mold for casting them. The sides of the mold consisted of three vertical sections, the core of a monolithic hollow piece, and the base of a single solid slab. About 10 tons of plaster of Paris were used in making the forms, the model, and the finished mold. Each pot was made from 2,500 pounds of domestic clays and feldspar blended in the following proportions:

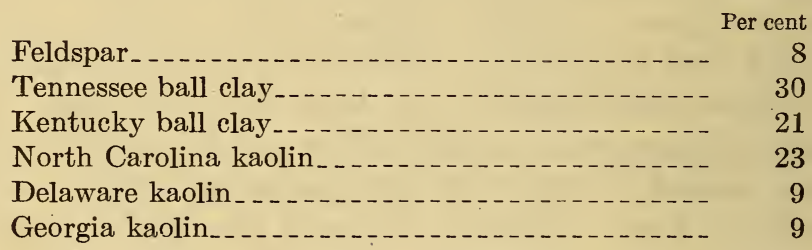

The clays were thoroughly blunged with water to which 0.6 per cent of water glass was added, and the resulting slip was poured into the mold. After standing in the mold for two days the core was withdrawn, and the next day the sides of the mold were removed. The pot was then slowly dried until most of the water had evaporated; finally it was air-dried for six months before being used. ${ }^{2}$

\section{THE MELTING FURNACE}

The furnace (fig. 1) was an ordinary, down-draft, gas-fired, singlepot furnace of the regenerative type modified by building a series of flues in the floor, each alternate flue being connected at one end with the space over the checkerwork, the other end opening into the combustion chamber. By means of temporary dampers ( $S$, fig. 2) over the checkerwork, the heated air and products of combustion were forced to travel down the outside of the pot and through the flues underneath it, thus establishing a more uniform temperature around and under the pot during the initial burning than would have been obtained by radiation alone; after the pot had been burned to about $1,000^{\circ} \mathrm{C}$. the temporary dampers were removed, and the furnace was then operated as an ordinary regenerative furnace.

\footnotetext{
1 The Equipment of a Casting Plant for the Manufacture of Glass Pots, by F. H. Riddle, J. Am. Ceram. Soc., 2, p. 8; August, 1919.

${ }^{2}$ A more complete description of the making of these pots can be found in Ceramic Ind., pp. 186-187; September, 1924.
} 
B. S. Journal of Research, RP97

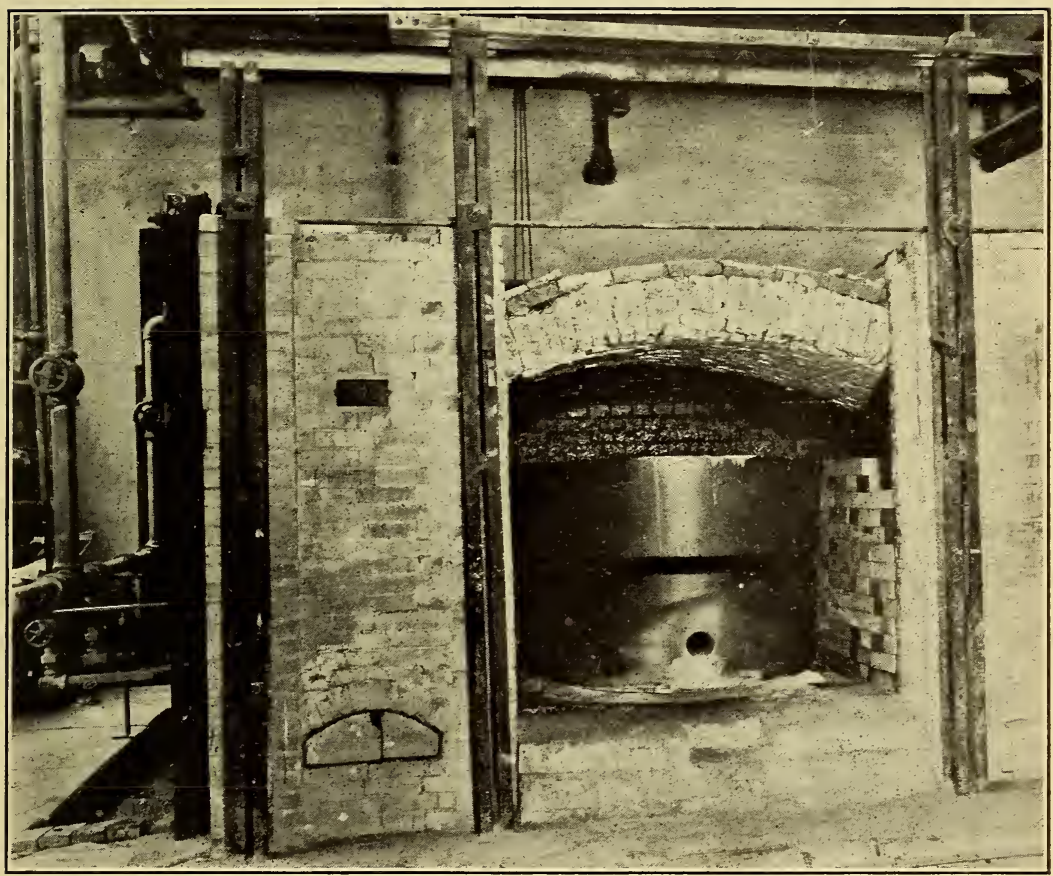

Figune 1.-The melting furnace (front removed) and pot after the glass had becn made

The shiny surface on the bricks which appears just above the pot is "glass" impregnated with corundum crystals. This is a characteristic condition in glass-making furnaces, and is the result of fluxing action produced by volatilized compounds, such as soda, from the glass on the refractories.

318-1 
B. S. Journal of Research, RP97

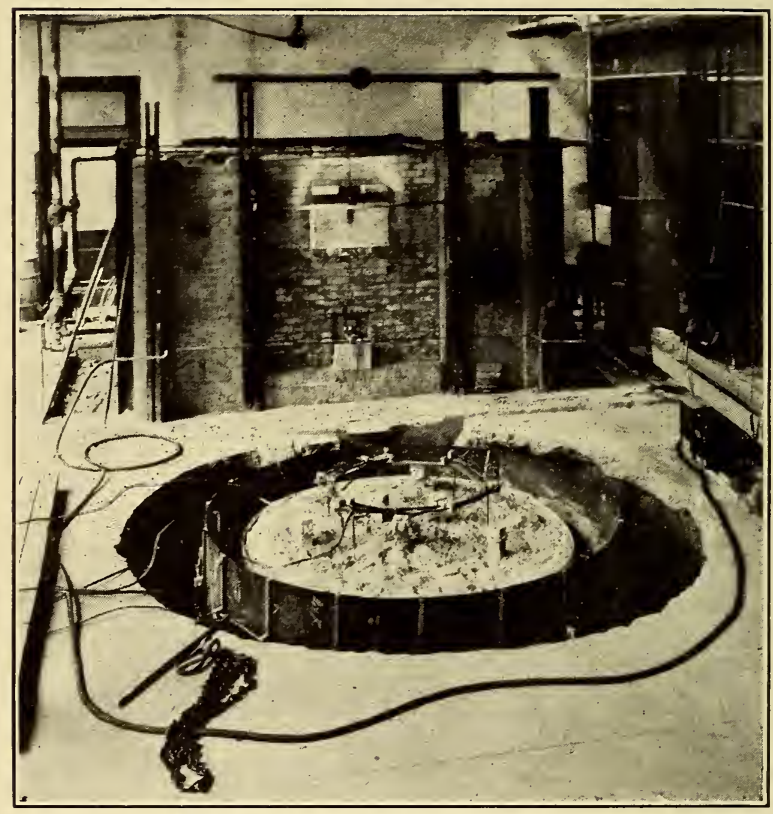

FIGURE 3.-The melting furnace (back), the assembled mold and annealing furnace (center) and the trough (right)

This picture was taken just before the lid was removed preparatory to casting the glass.

318-2 


\section{ESSENTIALS OF METHOD FINALLY USED}

In the original method the pots were used as cast, but in the method finally employed it was necessary to provide a hole near the base of the pot which could be plugged during the melting of the glass and through which the glass could be tapped when the plug was removed. This hole was conical, the small diameter being on the inside of the pot, and it was made before the burning of the pot was started. The plug for this hole consisted of a hollow, truncated cone turned from a block of steel and provided with two pipes in the larger base to permit rapid and continuous circulation of water in the plug. The dimensions of such a plug must, of necessity, be based on the dimensions of the hole after the pot is burned, but since the shrinkage of the pot

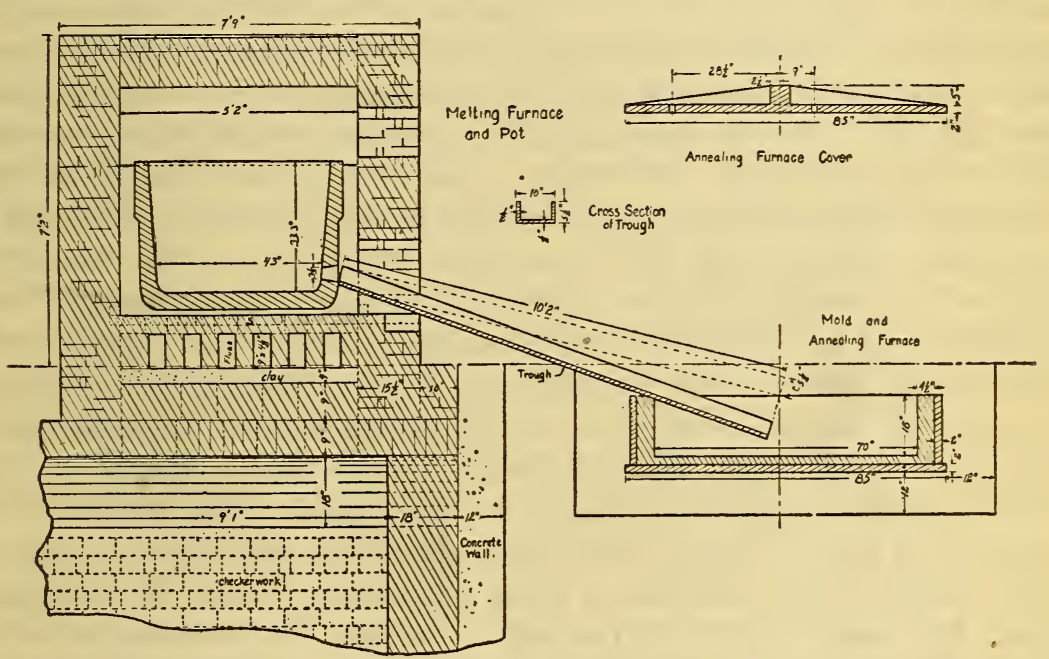

FIGURE 2.-Essential features of equipment used in making a 70-inch disk of glass

body from air-dried to burned condition was known to be about 8.5 per cent, the dimensions of the plug required could be predicted fairly accurately from those of the hole before burning. Furthermore, it is not essential that the dimensions of the hole and plug should be the same, but the tapers of both should be practically the same, and the small diameter of the plug should be such that the plug, when firmly seated in the hole, could not reach beyond the inner surface of the pot. In this particular case the hole in the pot was made about 5 inches in diameter at the large end and had a taper of about $812^{\circ}$. The plug was about $3 \frac{3}{4}$ inches long.

The combined mold and annealing furnace (fig. 2) into which the glass was tapped consisted of four essential parts: (1) The metal forms, (2) the lining, (3) the heating elements, and (4) the insulation. 
The metal forms were made of cast iron and consisted of a top, a ring, and a base. The top, which was 85 inches in diameter and 2 inches thick, was flat on the lower surface and had six radial ribs on the upper surface; these ribs were joined at the center of the upper surface in a cylinder 5 inches high and 5 inches in diameter and tapered to the surface of the top at its edge. (Fig. 2.) The ring was 79 inches in diameter (inside), 2 inches thick, and 19 inches high. The base was the same as the top except that it was not ribbed. The base, ring, and top were drilled and tapped for eyebolts to facilitate handling.

Six equidistant holes, one-fourth inch in diameter and approximately 2 inches deep, were drilled in the edges of both the base plate and of the top. Six similar holes were drilled into the ring halfway between its top and bottom. These holes were all for thermocouple installations. In each rib about 20 inches from the center of the top a one-fourth-inch hole was also drilled, two being used for thermocouples and the other four to accommodate supports for the frame carrying one of the power lines. Six 2-inch holes were drilled through the top between the ribs, three of these being 9 inches from the center and in alternate segments, the other three being $281 / 2$ inches from the center and in the remaining three segments. These were to permit local inspection of the glass during the cooling. They were covered with thin fused quartz disks mounted in closely fitting sheet asbestos frames and were held in place by hollow rectangular fire-clay tubes 14 inches long, which also prevented the insulation spread on the surface of the top from covering the quartz disks. The tops of these tubes were kept covered with sheet asbestos so that there would be very little, if any, heat loss at these peepholes. After all the equipment had been placed on the top, 5 inches of diatomaceous silica were added for thermal insulation. This was retained at the edges by strips of asbestos board fastened around the casting with a steel strap.

The lining for the mold was very fine grained, friable brick $(21 / 4$ by $4 \frac{1}{2}$ by 9 inches) made from ground, bonded, and burned diatomaceous silica. The heating elements consisted of spirals of No. 16 gage nickel-chromium wire mounted in grooved refractory plates (9 by 14 inches), each element having a resistance of about $13.5 \mathrm{ohms}$.

\section{PLACING AND ASSEMBLING THE MOLD}

Since the floor of the melting furnace was only slightly higher than the floor of the furnace room, a pit to contain the mold was dug in front of the furnace so that the glass might flow freely from the melting pot to the mold. This pit was about 15 feet in diameter and 4 feet deep.

A sheet-metal "can" without top or bottom, 109 inches in diameter and 48 inches deep, was placed in the pit, and inside the can a layer 
of carefully packed diatomaceous silica 1 foot thick was placed on the ground. Eighteen heating elements were so placed on the insulation that they would be symmetrically arranged under the base plate and be so distributed that each element would heat approximately an equal area of the base plate. The leads from each element were ultimately connected to the power line after bringing them through holes previously drilled in the can at the proper level. The base plate was put in position over the heating elements and the ring put in place concentrically with respect to the plate. Eighteen heating elements were fastened around the outside of the ring, and the leads from each one of these elements were also carried out through small holes in the can. The space between the ring and the can was then filled with powdered insulation which was not packed.

The bricks for the bottom of the mold were laid without mortar and in the herringbone style on the $41 / 2$ by 9 inch face, care being taken to have the bricks very well fitted and to keep the upper surface level. After the entire base was covered in this manner, the sides were laid up to give a wall 15 inches high and $41 / 2$ inches thick. Each brick in the wall was so cut at the ends that the wall conformed nearly to the curvature of the ring. The top of the furnace was provided with 18 heating elements placed similarly to those under the bottom, the leads from each plate being brought up to a wooden framework supported about 18 inches above the casting by rods fitted into the holes drilled in the ribs of the casting. (Fig. 3.)

The channel which was used for conveying the glass from the pot to the mold was 5 inches deep, 10 inches wide, and 10 feet 2 inches long. It was made by cutting off both flanges from one side of a standard 10 -inch $\mathrm{H}$ beam (55 lbs./ft.). It was very carefully sand blasted to remove all traces of rust and scale so that the glass might flow without being contaminated with iron oxide and without the possibility of scale snapping off as the metal became heated. The channel was supported near both ends from an overhead crane with flexible steel cable over pulleys in such a way that the elevation of either end could be controlled independently.

\section{TEMPERATURE MEASUREMENTS}

The temperature of the melting furnace was determined both with thermocouples connected to a portable potentiometer and with an optical pyrometer. During the initial burning of the pot 10 chromelalumel thermocouples were used-4 near the upper edge of the pot, 4 near the bottom (outside), 1 inside the pot near the bottom, and 1 in the sand under the pot. When the temperature of the furnace reached $1,000^{\circ} \mathrm{C}$., these couples were removed and a platinum to platinum-rhodium couple was used during the final burning of the pot. This couple projected through the back wall of the furnace and was 
about 18 inches above the furnace floor. It was also used during the melting of the glass to indicate constancy of temperature, while the optical pyrometer was relied on to indicate the average temperature.

Temperatures of the annealing furnace were measured with chromel-alumel thermocouples connected to a portable potentiometer. The installation of the thermocouples in each section of the furnace was made before the insulation above the base plate was put in place. In order to prevent breakage of the thermocouple protection tubes by a possible settling of the furnace, they were not brought out through the sides of the can but the couples and tubes were made long enough to reach from their positions in the castings to the upper edge of the can. The thermocouples and protection tubes in the ribs and sides of the top extended straight up through the insulation. One thermocouple whose hot junction was about one-fourth inch below the upper surface of a brick in the base of the mold and about 15 inches from the ring was brought out between the ring and the base and carried up to the edge of the can. In this case two tubes were used, one for each wire, because it has been found that protection tubes not closed at the inner end and extending through insulating material are liable to collect a small amount of water in the cold end and produce erratic readings; but if two tubes are used, there is no reason to believe that collected water in either or both affects the readings. All couples were connected with a switchboard by means of compensating or extension lead wires, and proper cold junction corrections were made. The cold junction for this work was in a pipe driven about 12 feet into the ground where the temperature did not change more than $2^{\circ} \mathrm{C}$. during the entire operation.

Although 22 couples were installed, it soon became evident that it was not necessary to use more than 5 of them, because the temperature of the furnace was sufficiently well indicated by these 5 . However, occasional checks were made on all couples, using an independent short connection to the potentiometer.

\section{HEATING CURRENT INSTALLATION}

Arrangements were made to supply, if necessary, a maximum of about 50 kilowatts to the annealing furnace in case the preheating of the furnace and the heat from the molten glass did not bring the furnace temperature well above $600^{\circ} \mathrm{C}$. From the main switchboard three lines were run to the furnace. Two of them were placed around the can, one at about the elevation of the base plate and the other opposite the middle of the ring. The third extended to the framework above the top of the furnace. Since the leads from each heating element were brought outside of the furnace, it was possible to connect each element across the leads or to connect them in series as current requirements dictated. By making series connections, 
the 18 heating elements on each of the three circuits could be connected in groups of $2,3,6,9$, or 18 elements each and thus reduce the use of external resistance without disturbing temperature distribution. Power consumption of the furnace was measured with ammeters and voltmeters so that the amount of energy being used in each of the three sections of the furnace could be determined and, by means of external resistance, controlled. A diagrammatic plan of the electrical installation is shown in Figure 4.

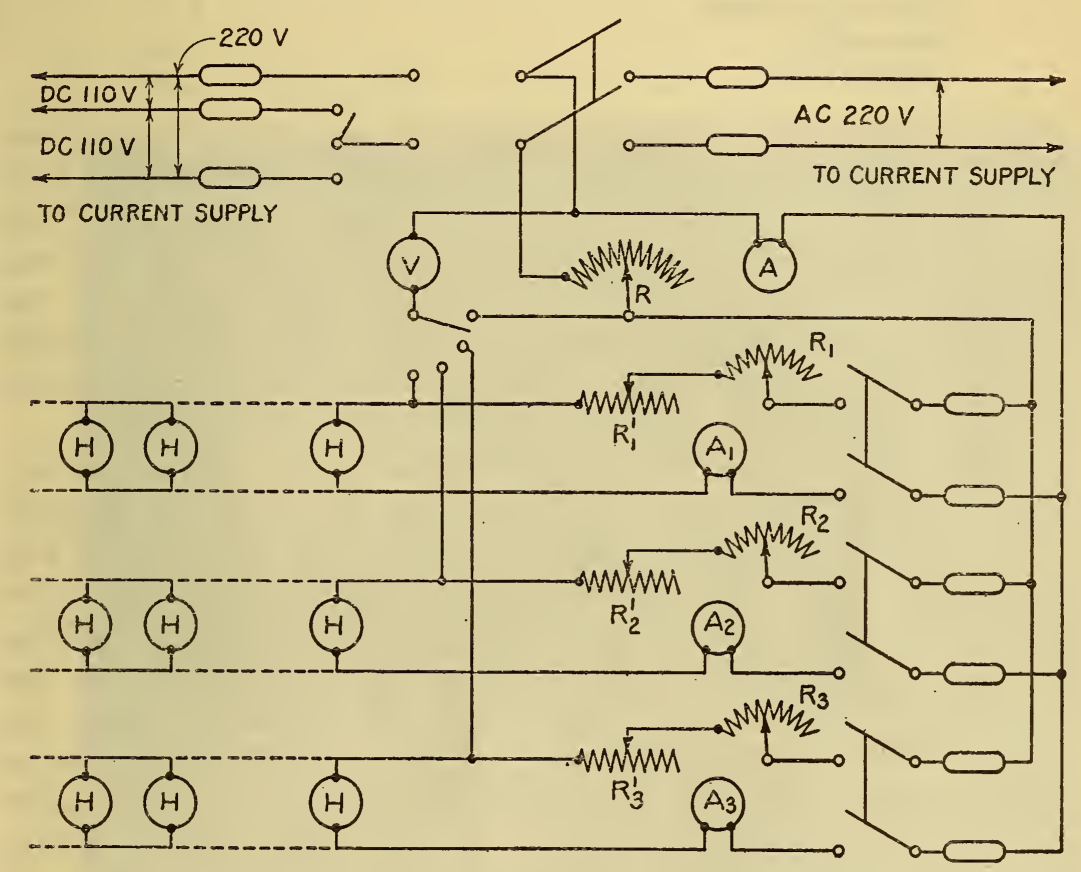

FIgure 4.-Diagrammatic plan of electrical installation

$H$, Heating elements; $V$, voltmeter; $A$, ammeter; $R$, variable external resistance.

\section{PROCEDURE}

All the equipment being ready, the burning of the pot was started. Since it was necessary to burn the pot without cracking it and since there was no method of adequately examining it after burning, it was necessarily burned very slowly, 30 days being required to reach a temperature of $1,425^{\circ} \mathrm{C}$., at which the glass would be melted. After the pot was properly burned at this temperature the lower door in the furnace was opened, the water-cooled plug was fastened in place, and 1,000 pounds of cullet were put into the pot. This was sufficient to fill the pot to a point above the hole and plug, and, since no leak 
was evident, the filling of the batch at the rate of 170 pounds per hour was started. The batch had the following composition:

\begin{tabular}{|c|c|}
\hline Sand & $\begin{array}{c}\text { Per cent } \\
499\end{array}$ \\
\hline Boric acid & 4. 3 \\
\hline Borax & 17.5 \\
\hline Soda ash & 5. 7 \\
\hline Potash (83 per cent) & 12. 0 \\
\hline Barium carbonate & 1.9 \\
\hline Potassium nitrate & 6.5 \\
\hline Zine oxide & 1. 9 \\
\hline Arsenic oxide & .3 \\
\hline
\end{tabular}

Approximately 5,000 pounds of batch were used, requiring 31 hours to fill the pot. The temperature of the melting furnace was then reduced to $1,400^{\circ} \mathrm{C}$., and the stirring of the glass was started. This was done by hand, using a water-cooled iron stirring rod, and was continued for six hours. The stirring was then stopped and the temperature of the furnace reduced to $1,350^{\circ} \mathrm{C}$. While the batch was being filled and the glass was being stirred, current was applied to the annealing furnace to heat and to hold it at about $400^{\circ} \mathrm{C}$.

Figure 5 gives some idea as to the equipment used during stirring. The water-cooled stirring rod projecting into the furnace can be seen, and also the temporary flooring, placed over the mold, which was necessary to provide access to the furnace from the front. The time which elapsed between the end of the stirring and the actual tapping of the glass was greater than it should have been because, after the stirring was stopped, it was necessary to remove the flooring; the rails on which it was supported, and the lid of the mold, and to swing: the channel into place. If this work were repeated, it would be more desirable to tap the pot from the side of the furnace opposite to that used for filling and stirring, so that the stirring might be continued until the glass was being tapped. By so doing, the prospects of getting glass relatively free from cords would be improved.

\section{CASTING AND ANNEALING THE GLASS}

When all arrangements were completed for tapping the pot, the supports for the water-cooled plug were released and the plug removed. The glass in contact with this plug was practically solid, and the molten glass did not begin to flow from the pot until the plug of cold glass became soft enough to yield. After it had become soft enough, the glass flowed very rapidly. As its level in the mold rose, the ends of the channel were adjusted so that one end remained practically fixed at the hole in the pot and the other was not permitted to touch the glass in the mold. (Fig. 6.) When practically all the glass 
B. S. Journal of Research, RP97

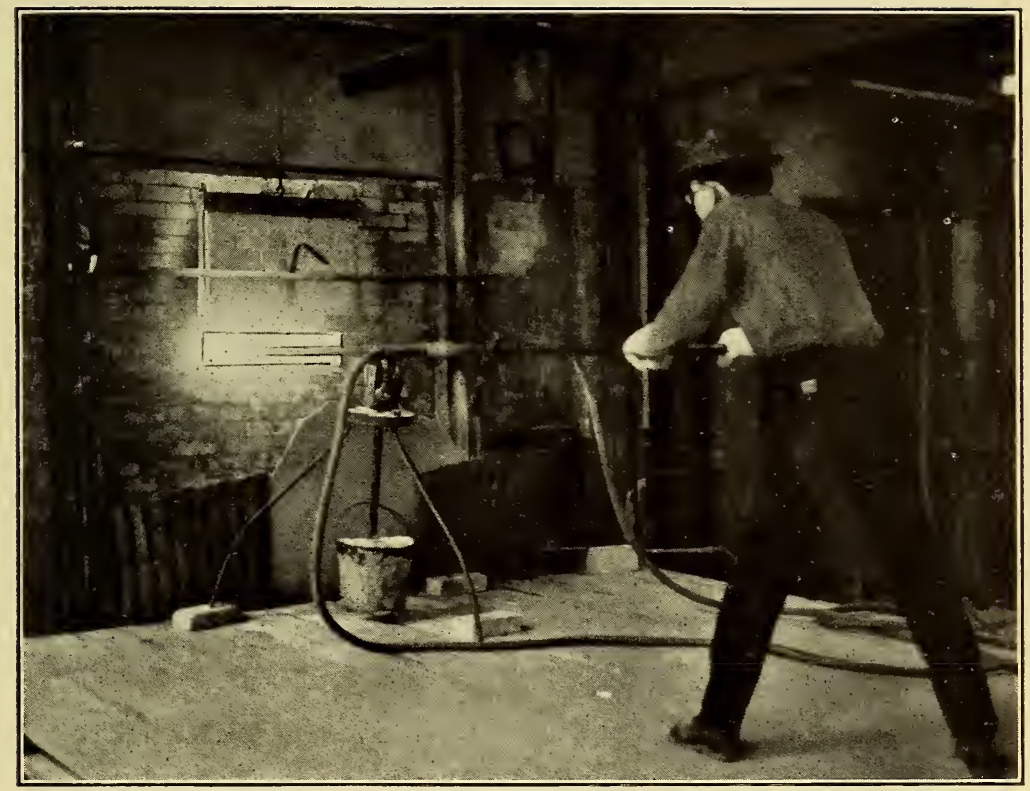

FIgURE 5.-Stirring the molten glass to increase its homogeneity $324-1$ 
B. S. Journal of Research, RP97

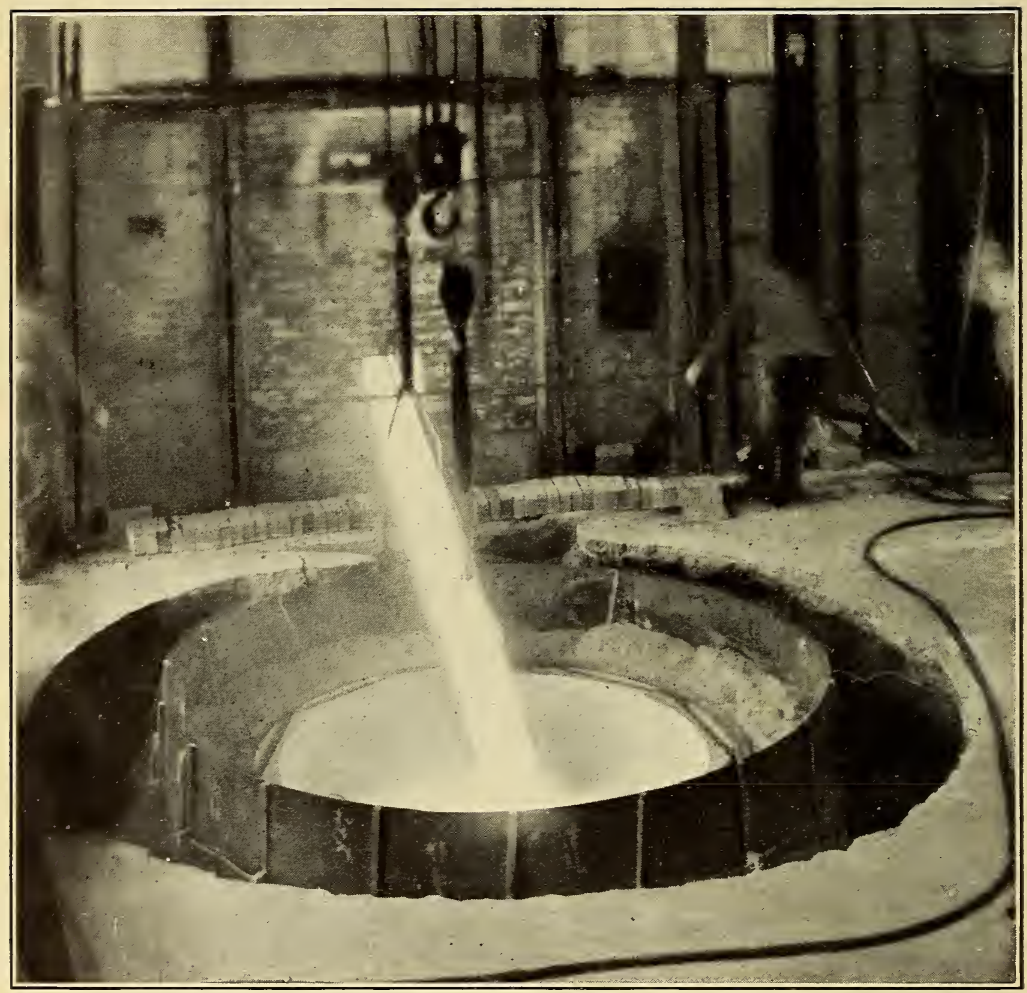

Figure 6.-The initial flow of the molten glass from the pot to the mold 324-2 
was in the mold, the trough was removed and the lid was put in place as quickly as possible to conserve a maximum amount of heat furnished by the glass. This was not a good procedure, because shortly after placing the lid on the mold it cracked in two places on account of too rapid heating, but fortunately this produced no undesirable results.

The maximum temperatures ever indicated by the thermocouples were about $850^{\circ} \mathrm{C}$. in a rib of the lid and about $1,000^{\circ} \mathrm{C}$. immediately below the surface of the brick in the bottom of the mold. At this time there were only the original 5 inches of insulating material on the top, but 24 hours later about 3 inches more of insulation were added. Nine hours later additional insulation was added until all metal parts of the mold were covered to a depth of 12 inches. The heat loss was then so slow and the amount of heat to be lost by the glass before reaching $600^{\circ} \mathrm{C}$. was still so large that it was not necessary to use heating current for about four days, at which time it was applied intermittently to equalize the temperature of the system.

Since borosilicate crown glass of the composition used in this work can be cooled safely to $600^{\circ} \mathrm{C}$. without danger of breaking, it was cooled to this temperature as rapidly as the furnace construction would permit, but without allowing any part of the furnace to cool below $600^{\circ} \mathrm{C}$. Eight days after casting the glass the average temperature of the furnace was $596.7^{\circ}$ C. ${ }^{3}$ Three days later the average temperature was $594.8^{\circ} \mathrm{C}$. In the meantime the power supplied to the heating elements was 2,752 watts. During the next two months the heating current was gradually reduced until the temperature for annealing $\left(461^{\circ} \mathrm{C}\right.$.) was reached.

This temperature was based on the data of Adams and Williamson, ${ }^{4}$ who have shown that glass can be most efficiently annealed if the annealing temperature and subsequent cooling rates are properly chosen. Although the time required for stresses or strain in glass to disappear at temperatures just below the initial softening point of the glass is very short (say, two minutes), it increases rapidly as the annealing temperature is lowered. However, the authors cited demonstrate that glass can be cooled more rapidly after annealing at lower temperatures than it can be after annealing at higher temperatures. Ultimately, then, the time required for the whole operation (annealing and cooling) may be shortened if lower annealing temperatures and faster cooling rates are used. The most desirable

\footnotetext{
${ }_{3}$ Temperature measurements are probably correct within $2^{\circ} \mathrm{C}$. Changes in temperature could, of course, be determined more accurately than this. The potentiometer scale was graduated in $0.1 \mathrm{~m} \nabla$, corresponding to $2.3^{\circ} \mathrm{C}$., and could be read to $0.02 \mathrm{mv}$.

4 J. Frank. Inst., 190, pp. 597-631 and 835-870; 1920.
} 
annealing temperature for a piece of glass of any thickness can be computed from the following equations:

$$
\log A=M_{1} \theta_{0}-M_{2}, A=\frac{0.047}{C} \text {, and } C=4.6 B a^{2}
$$

in which $\theta_{0}$ is the desired annealing temperature $\left({ }^{\circ} \mathrm{C}.\right), a$ is half the thickness of the glass (in centimeters), and $M_{1}, M_{2}$, and $B$ are constants whose values for borosilicate crown glass are $0.03,18.68$, and $2.85(10)^{-7}$, respectively. ${ }^{5}$ The time $(t)$, in minutes, required for annealing or release of stress is found from

$$
t=\frac{0.37}{A}
$$

The initial cooling rate $\left(h_{o}\right)$ after annealing is $\frac{5.2}{C} \circ \mathrm{C}$. per minute, and the permissible cooling rate $(h)$ at any temperature $(\theta)$ below the annealing temperature $\left(\theta_{o}\right)$ is obtained from

$$
h=\frac{h_{o}}{2}\left(1+2^{x}\right), \text { in which } x=\frac{\theta_{o}-\theta}{20}
$$

Since Adams and Williamson based their findings on pieces of glass much smaller than the piece being annealed, and since the validity of extrapolations from data obtained on small pieces to those for a much larger piece might be questionable, it was decided to anneal the glass about twice as long as computations indicated would be necessary and to cool it initially at about one-half the computed rate. The annealing temperature and cooling rates were based on a thickness of $31 \mathrm{~cm}$, which was slightly greater than the actual thickness of the disk. It was felt that these safety factors would also offset the effect of any differences between the temperature of the glass and the metal castings in which the thermocouples were placed and of any inequalities in the temperature of the castings not indicated by the thermocouples.

The glass was annealed for 41 days at $461^{\circ} \mathrm{C}$., the total power consumption during this time being 1,890 watts, distributed as follows: 660 watts on the bottom of the furnace, 444 on the ring, and 786 on the top. During the annealing period constant personal attention was given to the annealing furnace in order to adjust the heating current as frequently as might be made necessary by changes in the voltage of the power line. The care with which this was done is shown by the following: The average temperature of the furnace during the 41 days used in the annealing operation was $461.5^{\circ} \mathrm{C}$., the

'In this presentation, $A$ may be called the "annealing constant" and depends on the rate at which glass anneals when held at constant temperatures. $M_{1}$ and $M_{2}$ are constants obtained by plotting $\log A(10)^{5}$ against temperature. $B$ is a function of the birefringence produced by a given stress. In a paper of this kind a more comprehensive mathematical discussion would be out of place, and the reader is referred to the work previously cited. 
maximum average ${ }^{6}$ on any day was $463.4^{\circ} \mathrm{C}$., and the minimum was $458.3^{\circ} \mathrm{C}$.

\section{FINAL COOLING}

Assuming that the glass at the end of the annealing period was free from strain, it still was necessary to cool it so slowly that no great amount of strain would be present at the end of the operation. Although the data of Adams and Williamson indicated that an initial cooling rate of $2.33^{\circ} \mathrm{C}$. per day and a maximum rate of $60^{\circ} \mathrm{C}$. per day would be permissible, it was decided that the initial cooling rate used should be about $1^{\circ}$ per day and the maximum rate should not exceed $10^{\circ}$ per day; and, if possible, this maximum would be restricted to $6^{\circ}$ per day.

Cooling was first accomplished by reducing the power consumption 5 per cent of that required to maintain the constant annealing temperature and by applying this reduced amount of power until the temperature drop became definitely slower than it was at the beginning. Generally five days were required to show a definite decrease in the cooling rate. Sixteen similar cuts of 5 per cent each were made in the heating power, after which the amount of each cut was reduced to 2.5 per cent until the power used was only 5 per cent of that used for annealing. Finally, cuts were made at the rate of 1 per cent. It was thought that the very slow cooling at lower temperatures was necessary because, in the final equalization of any unknown temperature differences in the system, temporary strains might develop in the glass which would be sufficient to break it, and this, of course, must be avoided if possible

The uniformity of temperature maintained during cooling is indicated by the following table:

\begin{tabular}{|c|c|c|c|c|c|c|c|}
\hline & \multicolumn{5}{|c|}{ Temperatures at different parts of the furnace } & \multirow{2}{*}{$\begin{array}{c}\begin{array}{c}\text { Average } \\
\text { tempera- } \\
\text { ture }\end{array} \\
{ }^{\circ} C . \\
611.7 \\
613.1 \\
610.2\end{array}$} & \multirow{2}{*}{ 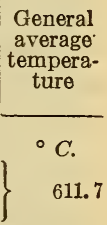 } \\
\hline 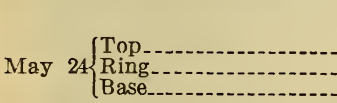 & $\begin{array}{l}{ }^{\circ} C . \\
610.5 \\
614.0 \\
610.5\end{array}$ & $\begin{array}{l}{ }^{\circ} C . \\
611.7 \\
614.0 \\
610.5\end{array}$ & $\begin{array}{l}{ }^{\circ} C . \\
611.7 \\
611.7 \\
608.1\end{array}$ & $\begin{array}{l}{ }^{\circ} C . \\
612.8 \\
612.8 \\
608.1\end{array}$ & ${ }^{\circ} C$. & & \\
\hline July $8\left\{\begin{array}{l}\text { Top } \\
\text { Ring } \\
\text { Base }\end{array}\right.$ & $\begin{array}{l}465.7 \\
468.7 \\
466.4\end{array}$ & $\begin{array}{l}466.4 \\
468.0 \\
466.4\end{array}$ & $\begin{array}{l}466.4 \\
468.0 \\
465.3\end{array}$ & $\begin{array}{l}468.7 \\
465.3\end{array}$ & 463.4 & $\begin{array}{l}466.2 \\
468.4 \\
465.4\end{array}$ & 466.7 \\
\hline Nov. $19\left\{\begin{array}{l}\text { Top } \\
\text { Ring } \\
\text { Base }\end{array}\right.$ & $\begin{array}{l}176.9 \\
177.2 \\
176.2\end{array}$ & $\begin{array}{l}176.7 \\
176.9 \\
176.7\end{array}$ & $\begin{array}{l}175.7 \\
176.9 \\
176.0\end{array}$ & $\begin{array}{l}177.4 \\
177.2 \\
176.5\end{array}$ & 178.2 & $\begin{array}{l}177.0 \\
177.1 \\
176.4\end{array}$ & 176.8 \\
\hline
\end{tabular}

Temperatures for record were usually read only once a day. The average temperature for the day was obtained by averaging all temperatures recorded on that day. 


\section{INSPECTION DURING COOLING}

When an attempt was made to project light through one of the peepholes in the top of the furnace and view the glass through another, it was found to be practically impossible because the lower surface of the quartz disks had been slightly etched by volatile materials, such as alkali or boric oxides from the hot glass. After the disks were removed, resurfaced, and replaced, illumination and inspection of the glass through these peepholes was very easily accomplished, but the glass could only be examined in the relatively small parts immediately below the peepholes. However, a sufficiently good view could be obtained to justify the conclusion that the glass was still intact.

Four and one-half months after the cooling from the annealing temperature started, the furnace and its contents were practically at room temperature. The surface insulation and the lid of the furnace were then removed and the glass was found to be in satisfactory condition. The disk was 69.75 inches in diameter, 11 inches thick, and weighed approximately 4,000 pounds.

\section{QUALITY OF ANNEALING}

The disk was removed from the mold and the bricks, which were superficially fused to the glass, were stripped off. (Fig. 7.) This left the sides and bottom of the disk opaque, because the glass had partially fused to the bricks. Before an examination for strain could be made it was necessary to grind the bottom of the disk with carborundum and water to remove the adherent particles of brick. The disk was then placed on edge in a wooden frame and the ground surface coated with a heavy mineral oil which rendered it sufficiently transparent to permit examination with polarized light. The magnitude of the residual strain was measured by examining small sections of the entire disk. (Fig. 8.) The distribution or symmetry of strain was determined by projecting a divergent beam of polarized light against one surface of the disk and examining it through a nicol prism from the opposite side. In this case the light source and observer were each about 30 feet from the disk, and the entire disk was visibly through the nicol prism. The interference figure was very symmetrical with respect to the disk, intersecting exactly in its center, and the maximum strain detected produced a relative retardation equivalent to about $6 \mathrm{~m} \mu$ per centimeter of thickness. This is well within the maximum strain permissible in optical glass used for optical instruments of highest precision.

\section{DRILLING THE HOLE}

Large reflecting telescopes are generally equipped with one of three types of mountings - namely, the prime focus, Newtonian, and Cassegrainian. The last of these requires a hole in the center of the 
B. S. Journal of Research, RP97

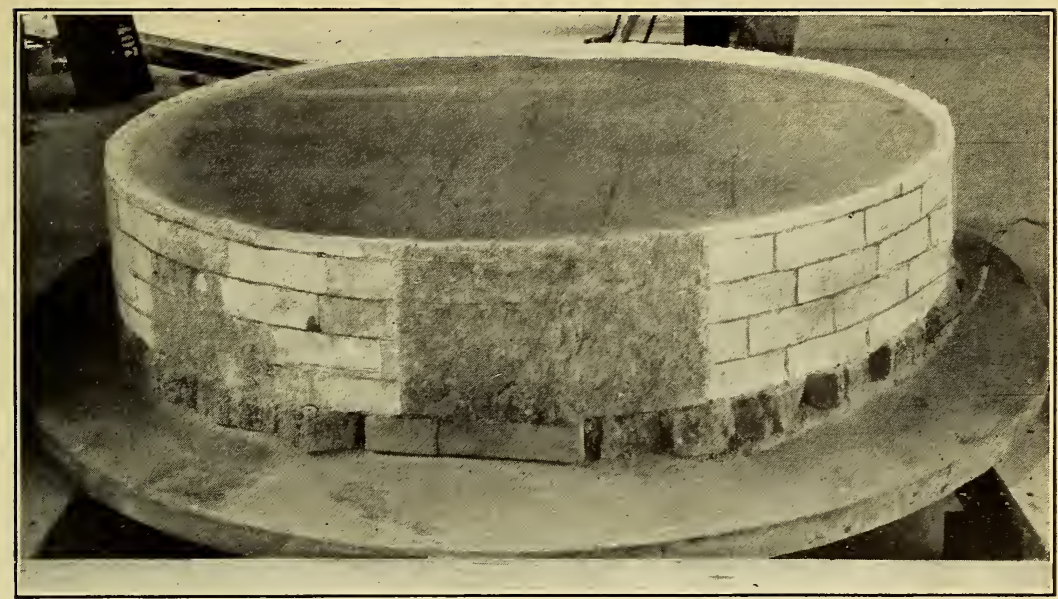

FIGURE 7.-The disk as it appeared after removing most of the adhering bricks from the side

It is still resting on the bottom bricks and cast-iron base.

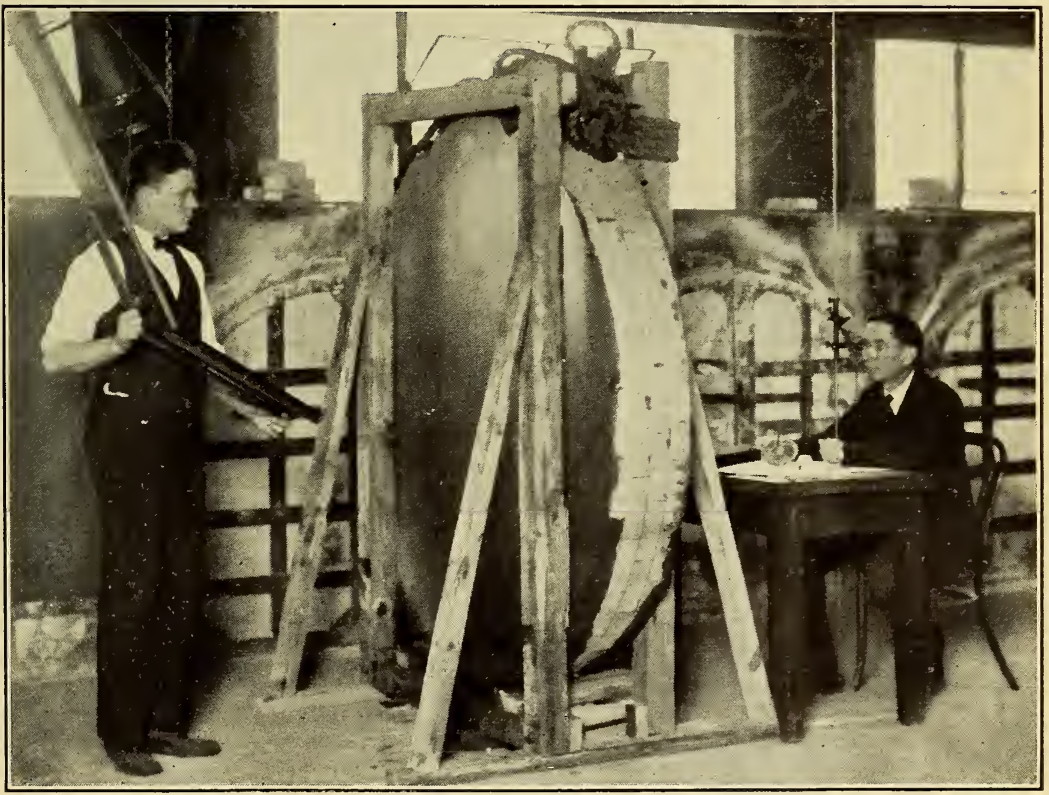

FIGURE 8.-Examining the glass for strain

$328-1$ 
B. S. Journal of Research, RP97

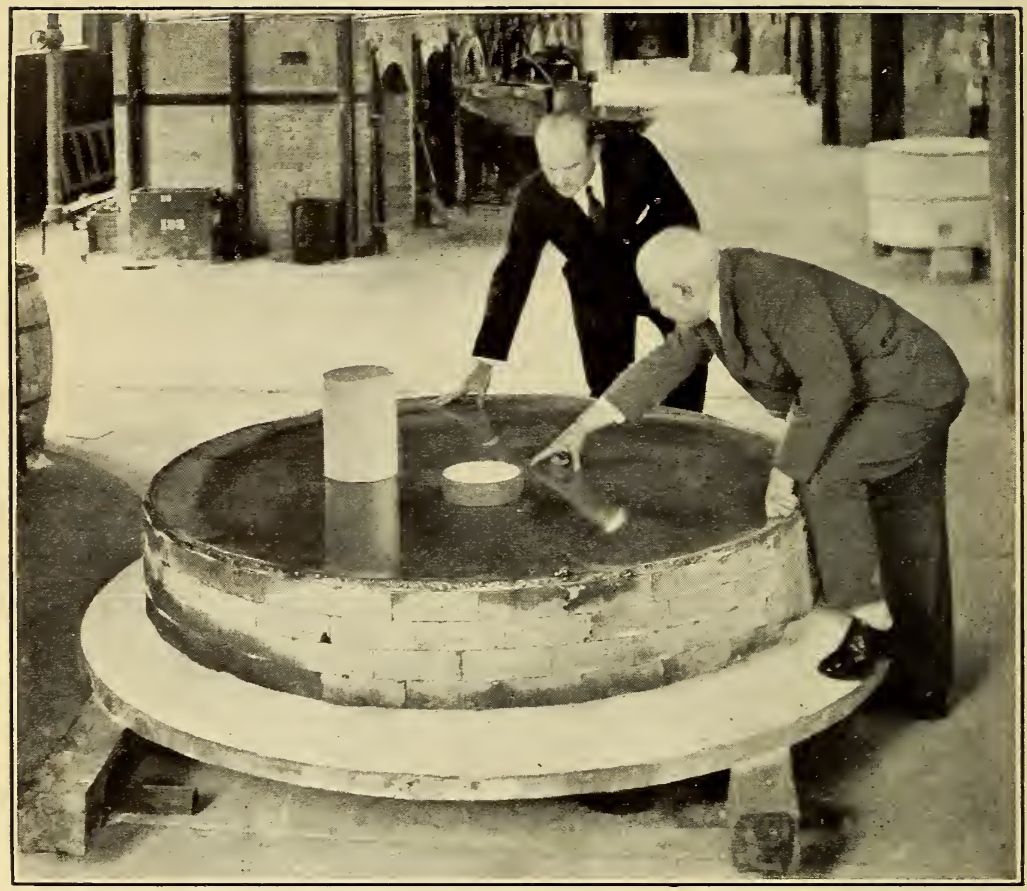

Figure 9.-Dr. George K. Burgess, Director of the Bureau of Standards (right), and Dr. C. C. Crump, Professor of Astronomy at Ohio Wesleyan University, examining the disk after the hole had been cut

The "core" is resting on the surface of the disk.

$328-2$ 
reflector so that light concentrated by the reflector may be returned by a secondary mirror to a point back of the reflector. This hole does not interfere with the use of the other mountings, but without it the Cassegrainian mounting could not be used. Hence, it was decided to drill an 8-inch hole in the center of this disk, although several authorities said this could not be done without a very great possibility of breaking the disk. A possible cause of breakage during this operation lies in the fact that in cutting a hole the surface of the cut is very finely fractured; the fractures, being near the center of the disk and in the zone of high tensional stresses, may easily become the starting point of serious cracks if the glass is not sufficiently free from strain.

The drilling was accomplished by attaching an 8-inch brass tube to a radial drill press and by slowly cutting out a core, using water and 150-mesh carborundum in the cut. About 70 working hours were required to cut this hole. (Fig. 9.) It might have been done in much less time, but, by working slowly, a partial adjustment of the glass to unbalanced stresses could take place and the possibilities of excessive local heating would be reduced.

This operation was conducted without any apprehension of possible cracking of the glass, although precautions were taken to protect the optician working on it in case the glass did "explode." These precautions consisted of bedding the glass on sand and surrounding it entirely with sand contained in the cast-iron ring used in the mold. The top was covered with 2 by 12 inch planks and $1 / 2$-inch sheet steel, except for the hole through which the cutter passed.

\section{CONCLUSION}

Although the manufacture of large disks of glass to be used for reflectors in astronomical telescopes is ordinarily considered a difficult undertaking, it seems from the foregoing discussion that such is not the casẻ, provided sufficient time is taken to anneal and cool the glass properly.

Based on the results obtained in the work just reported, it seems quite possible that American manufacturers can easily go into this field of endeavor, if occasion presents itself, with reasonable assurance that their efforts will be successful and that they need not spend much time and money, if any, in developing a satisfactory method of operation.

Washington, February 16, 1929. 